\title{
Reconstituted Oral Solution Dosage Form
}

National Cancer Institute

\section{Source}

National Cancer Institute. Reconstituted Oral Solution Dosage Form. NCI Thesaurus. Code C68985.

A solution that requires reconstitution with a suitable solvent, and is intended for oral administration. 